\title{
Cannabinoid Receptor Activation in the Basolateral Amygdala Blocks the Effects of Stress on the Conditioning and Extinction of Inhibitory Avoidance
}

\author{
Eti Ganon-Elazar and Irit Akirav \\ Department of Psychology, University of Haifa, Haifa 31905, Israel
}

\begin{abstract}
Despite the efficacy of behavior therapy for human anxiety disorders, extinction-like treatments require repeated cue exposures and are vulnerable to reversal by a number of environmental factors, particularly stress. The endocannabinoid system has recently emerged as important in the regulation of extinction learning and in the regulation of the hypothalamic-pituitary-adrenal axis. Here, we aimed to examine the involvement of the cannabinoid $\mathrm{CB}_{1}$ receptor in the basolateral amygdala (BLA) in inhibitory avoidance (IA) conditioning and extinction and to test whether cannabinoid activation would reverse the effects of stress on these memory processes. The synthetic full agonist of the $\mathrm{CB}_{1} / \mathrm{CB}_{2}$ receptor WIN55,212-2 [R-(+)-(2,3-dihydro-5-methyl-3-[(4-morpholinyl)methyl]pyrol[1,2,3-de]-1,4benzoxazin-6-yl)(1-naphthalenyl) methanone monomethanesulfonate] $(5 \mu \mathrm{g} / 0.5 \mu \mathrm{l})$ microinjected into the BLA had no effect on IA conditioning or extinction by itself. However, microinjecting WIN55,212-2 into the BLA before exposing the rats to a stressor reversed the enhancing effects of the stressor on IA conditioning and its impairing effects on IA extinction. Importantly, WIN55,212-2 microinjected into the BLA reduced stress-induced elevations in corticosterone levels. Control experiments demonstrated the following: (1) the effects of WIN55,212-2 could not be attributed to sensorimotor deficits, because these parameters seemed unchanged by WIN55,212-2 microinjected into the $\mathrm{BLA}$; and (2) the $\mathrm{CB}_{1}$ receptor in the $\mathrm{BLA}$ is crucially involved in the extinction of $\mathrm{IA}$, because the $\mathrm{CB}_{1}$ receptor antagonist AM251 [ $N$-1-(2,4-dichlorophenyl)-5-(4-iodophenyl)-4-methyl- $N$-1-piperidinyl-1 $H$-pyrazole-3-carboxamide] $(6 \mathrm{ng} / 0.5 \mu l)$ microinjected into the BLA significantly blocked extinction. Together, our findings may support a wide therapeutic application for cannabinoids in the treatment of conditions associated with the inappropriate retention of aversive memories and stress-related disorders.
\end{abstract}

\section{Introduction}

Fear inhibition is most often studied through a procedure in which a previously fear-conditioned organism is exposed to a fear-eliciting cue in the absence of any aversive event. This procedure results in a decline in conditioned fear responses that is attributed to a process called extinction (Myers and Davis, 2007).

Despite the efficacy of behavior therapy for human anxiety disorders, extinction-like treatments require repeated cue exposures and are vulnerable to reversal by a number of environmental factors, particularly stress. We recently showed (Akirav and Maroun, 2007) that 30 min of exposure to the elevated platform stressor disrupts the extinction of both auditory and contextual fear conditioning. Others have reported that stress reduces cued fear extinction (Shumake et al., 2005; Izquierdo et al., 2006; Maren and Chang, 2006) or impairs its recall (Maren and Chang, 2006; Miracle et al., 2006; Garcia et al., 2008). In parallel, exposure to stress facilitates the initial fear learning, thus further enhancing the fear response (Shors et al., 1992; Cordero et al., 2003).

\footnotetext{
Received March 12, 2009; revised April 19, 2009; accepted June 9, 2009.

This work was supported by The National Institute for Psychobiology in Israel Grant 203-07-08 (I.A).

Correspondence should be addressed to Dr. Irit Akirav, Department of Psychology, University of Haifa, Haifa 31905, Israel. E-mail: irit.akirav@gmail.com.

DOI:10.1523/JNEUROSCI.1223-09.2009

Copyright $\odot 2009$ Society for Neuroscience $\quad$ 0270-6474/09/2911078-11\$15.00/0
}

Manipulation of the endogenous cannabinoid system has become a major focus of current search for novel therapeutics to treat many common mental illnesses, including anxiety disorders, depression, and drug addiction (Porter and Felder, 2001; Kathuria et al., 2003). It is generally appreciated that the recreational use of cannabinoids is related to their positive modulatory effects on brain-rewarding processes along with their ability to positively influence emotional states and remove stress responses to environmental stimuli (Gardner and Vorel, 1998). Indeed, the potential therapeutic value of cannabinoid modulation is underscored by the dense expression of the cannabinoid $\mathrm{CB}_{1}$ receptor in regions known to be significant for anxiety and emotional learning, particularly the basolateral amygdala (BLA) (Katona et al., 2001; Haller et al., 2002).

The endocannabinoid system has recently emerged as important in the regulation of extinction learning (Marsicano et al., 2002; Varvel and Lichtman, 2002; Suzuki et al., 2004; de Oliveira Alvares et al., 2005) and of the hypothalamic-pituitary-adrenal (HPA) axis and its end product corticosterone (CORT) (Patel et al., 2004; Cota, 2008; Steiner and Wotjak, 2008). Studies so far suggest that environmental stress and $\mathrm{CB}_{1}$ receptor activity interact in the regulation of the HPA axis and that the augmentation of endocannabinoid signaling can suppress stress-responsive systems (Patel et al., 2004; Cota, 2008; Steiner and Wotjak, 2008).

Our main goal was to test whether cannabinoid activation in the BLA would inhibit stress-induced alterations in inhibitory 
avoidance (IA) conditioning and extinction and to examine the possible association with the HPA axis. To that end, we examined the following: (1) the effects of administering cannabinoid receptor agonist into the BLA on the conditioning and extinction of IA, (2) whether cannabinoid activation in the BLA would reverse the effects of stress on IA conditioning and extinction, and (3) whether cannabinoid activation in the BLA would affect plasma CORT levels.

\section{Materials and Methods}

Subjects. A total of 434 male Sprague Dawley rats ( $\sim 60 \mathrm{~d}$ old, $250-300 \mathrm{~g})$ were used for the experiments. Animals were caged individually at $22 \pm$ $2^{\circ} \mathrm{C}$ under $12 \mathrm{~h}$ light/dark cycles. Rats had access to water and laboratory rodent chow ad libitum. The experiments were approved by the University of Haifa Ethics and Animal Care Committee, and adequate measures were taken to minimize pain or discomfort in accordance with the guidelines laid down by the National Institutes of Health in the United States regarding the care and use of animals for experimental procedures.

Drug treatments. Three drugs were investigated: the synthetic $\mathrm{CB}_{1} /$ $\mathrm{CB}_{2}$ receptor agonist WIN55,212-2 $[R-(+)-(2,3$-dihydro-5-methyl3 -[(4-morpholinyl)methyl]pyrol[1,2,3-de]-1,4- benzoxazin-6-yl)(1naphthalenyl) methanone monomethanesulfonate] (WIN); an inhibitor of endocannabinoid reuptake and breakdown, AM404 [ $N$-(4-hydroxyphenyl)-arachidonamide]; and the $\mathrm{CB}_{1}$ receptor antagonist AM251 [N-1-(2,4-dichlorophenyl)-5-(4-iodophenyl)-4methyl- $N$-1-piperidinyl-1 $H$-pyrazole-3-carboxamide] (Tocris Bioscience). Each drug was initially dissolved in dimethylsulfoxide (DMSO) and further diluted with saline $(0.9 \% \mathrm{NaCl})$.

The final DMSO concentration was $<7 \%$. This was also used as the vehicle. The final concentration of DMSO did not affect performance in the inhibitory avoidance task. Drug concentrations are based on reports in the literature (Martin et al., 1999; Chhatwal et al., 2005; de Oliveira Alvares et al., 2005; Moreira et al., 2007; Pamplona et al., 2008) and our preliminary results. For microinjection, WIN55,212-2 was used at 2.5 $\mu \mathrm{g} / 0.5 \mu \mathrm{l}, 5 \mu \mathrm{g} / 0.5 \mu \mathrm{l}$, or $10 \mu \mathrm{g} / 0.5 \mu \mathrm{l}$. AM 404 was used at $200 \mathrm{ng} / 0.5 \mu \mathrm{l}$ or $800 \mathrm{ng} / 0.5 \mu \mathrm{l}$, and AM251 was used at $6 \mathrm{ng} / 0.5 \mu \mathrm{l}$. For intraperitoneal administration, WIN 55,212-2 was used at $0.25 \mathrm{mg} / \mathrm{kg}$.

Cannulation and drug microinjection. Rats were anesthetized with 4.8 $\mathrm{ml} / \mathrm{kg}$ Equithesin $\left(2.12 \% \mathrm{w} / \mathrm{v} \mathrm{MgSO}_{4} 10 \%\right.$ ethanol, 39.1\% v/v propylene glycol, $0.98 \% \mathrm{w} / \mathrm{v}$ sodium pentobarbital, and $4.2 \% \mathrm{w} / \mathrm{v}$ chloral hydrate), restrained in a stereotactic apparatus (Stoelting), and implanted bilaterally with a stainless steel guide cannula (23 gauge, thin walled) aimed at the BLA (anteroposterior, $-3 \mathrm{~mm}$; lateral, $\pm 5 \mathrm{~mm}$; ventral, $-6.7 \mathrm{~mm}$ ). The cannulae were set in place with acrylic dental cement and secured by two skull screws. A stylus was placed in the guide cannula to prevent clogging. Animals were allowed 1 week to recuperate before being subjected to experimental manipulations.

For microinjection, the stylus was removed from the guide cannula, and a 28 gauge injection cannula, extending $1.0 \mathrm{~mm}$ from the tip of the guide cannula, was inserted. The injection cannula was connected via polyethylene PE20 tubing to a Hamilton microsyringe driven by a microinfusion pump (CMA/100; Carnegie Medicine). Microinjection was performed bilaterally in a $0.5 \mu \mathrm{l}$ volume per side delivered over $1 \mathrm{~min}$. The injection cannula was left in position for an additional $30 \mathrm{~s}$ before withdrawal to minimize dragging of the injected liquid along the injection tract.

Light-dark inhibitory avoidance. Animals were placed in an inhibitory avoidance apparatus with a metal grid floor. The apparatus was divided into a light side and a dark side, and the rats were placed in the light side, facing the left rear corner of the box.

For conditioning (Cond), when the rats crossed over to the dark side of the box (with four paws on the grid), they received a $2 \mathrm{~s}, 0.7 \mathrm{~mA}$ scrambled footshock. After administration of the footshock, the opening between the two sides of the box was blocked, and the rats remained in the dark side for an additional $60 \mathrm{~s}$, after which they were removed back to the home cage.

For extinction, rats were submitted to a non-reinforced test trial every $24 \mathrm{~h}$ for three days (Ext1-Ext3), beginning $24 \mathrm{~h}$ after conditioning. Each rat was placed in the light side of the box, and the time elapsed until it crossed over to the dark side (i.e., latency) was measured. If, after $180 \mathrm{~s}$, the rat did not cross over on its own, the experimenter gently guided it to the dark side. The opening between the two sides of the shuttle was then blocked, no footshock was administered, and the rat was allowed to explore the dark side freely for $180 \mathrm{~s}$, after which it was removed back to the home cage.

A drug (the $\mathrm{CB}_{1}$ receptor antagonist AM251 or one of the agonists WIN55,212-2 or AM404) was microinjected into the BLA at different time points to address various phases of memory processing. Drugs were administered 20 min before conditioning(Pre-Cond), 20 min before the first extinction trial (pre-Ext1), or immediately (i.e., $2 \mathrm{~min}$ ) after the first extinction trial (post-Ext1). The vehicle was administered at the same time points.

Elevated platform stress. An elevated platform $(\mathrm{EP})(12 \times 12 \mathrm{~cm})$ stressor was used to examine the effects of exposure to a stressful experience on IA conditioning and extinction. Individual animals were placed on an elevated platform for $30 \mathrm{~min}$ in a brightly lit room, which elicits stress responses in the form of behavioral "freezing," that is, immobility for up to $10 \mathrm{~min}$, defecation, and urination (Maroun and Akirav, 2008).

Exposure to the EP occurred immediately before conditioning (PreCond), immediately before Ext1 (Pre-Ext1), or immediately after Ext1 (Post-Ext1). The EP groups (i.e., EP Pre-Cond, EP Pre-Ext1, and EP Post-Ext1) experienced the EP stressor in the absence of any microinjection, whereas the WIN+EP groups were microinjected with WIN55,212-2, 2 min before experiencing the EP stressor. The vehicle groups were microinjected with vehicle when the WIN+EP groups received WIN but did not experience the EP stressor.

Open field. The open field consisted of a closed wooden box. The walls were painted black, and the floor was white and divided by $1-\mathrm{cm}$-wide black lines into 25 squares measuring $10 \times 10 \mathrm{~cm}$ each. A video image of the entire open field was displayed on a television monitor, and the movements of the rat, which was initially placed in a corner of the field, were manually recorded and analyzed to measure motor activity over a period of $5 \mathrm{~min}$. Recordings were made of the time the rat spent in the central and the peripheral squares, the number of instances of rearing, and the total distance covered. The open-field arena was thoroughly cleaned between each trial.

Rats were microinjected with the different drugs into the BLA and, after $20 \mathrm{~min}$, tested in the open-field arena. For rats that were placed on the $\mathrm{EP}$ for $30 \mathrm{~min}$ with or without previous microinjection of WIN55,212-2 into the BLA, the open-field test was performed immediately after the EP stressor.

Pain sensitivity. Pain sensitivity was assessed by determining the footshock intensity (in milliamperes) that elicited a discomfort response (i.e., flinch or vocalization) (Kim et al., 1991). Rats were individually placed in a Plexiglas box $(25 \times 25 \times 34 \mathrm{~cm})$ with a floor consisting of 13 stainless steel rods of $5 \mathrm{~mm}$ diameter, spaced every $1 \mathrm{~cm}$. Each rat received a continuously ascending mild electric footshock (beginning at $0.0 \mathrm{~mA}$ and ending as soon as the animal flinched or vocalized) via the metal grid floor to determine current thresholds at which each animal would exhibit a flinch or a vocalization response. Two observers scored flinch and vocalization thresholds. Rats were taken for the pain sensitivity test $5 \mathrm{~min}$ after the open-field test.

Corticosterone measurement. Trunk blood was collected after decapitation between 9:00 and 11:00 A.M. for 4 consecutive days (from onequarter of the rats per group per day). Samples were centrifuged at 3000 $\mathrm{rpm}$ for $20 \mathrm{~min}$ at $4^{\circ} \mathrm{C}$. Serum was stored at $-80^{\circ} \mathrm{C}$ and analyzed for CORT using ELISA kits (DSL Inc.).

Histology. On completion of the inhibitory avoidance experiments, the animals were deeply anesthetized with $4.8 \mathrm{ml} / \mathrm{kg}$ Equithesin (see above) and microinjected into the BLA with $0.5 \mu$ l of ink, to verify the location of the cannulae. Figure 1 shows a representative schematic drawing of the placements of the cannulae in the BLA (coronal view at position 3.14 and $3.30 \mathrm{~mm}$ posterior to bregma) (Paxinos and Watson, 1998).

Statistical analysis. The results are expressed as means \pm SEM. For statistical analysis, repeated-measures ANOVA, one-way ANOVA, and $t$ tests were used as indicated. All post hoc comparisons were made using the least-significant difference multiple-comparison test. 


\section{Results}

Cannabinoid receptor agonist WIN55,212-2 microinjected into the BLA has no effect on inhibitory avoidance conditioning or extinction First, we asked whether stimulation of cannabinoid receptor signaling in the BLA might accelerate the IA extinction rate or affect IA conditioning. Thus, vehicle or the $\mathrm{CB}_{1} / \mathrm{CB}_{2}$ receptor agonist WIN55,212-2 were microinjected into the BLA before conditioning, before Ext1, or immediately after Ext1.

Microinjecting vehicle into the BLA before conditioning, before Ext1, or immediately after Ext1 had no effect on the latency of the rats to enter the dark side of the box $\left(F_{(2,9)}<1\right.$; NS). Consequently, all vehicle groups for the light-dark IA experiments involving WIN55,212-2 (5 $\mu \mathrm{g} /$ $0.5 \mu \mathrm{l})$ were pooled for all analyses (vehicle, $n=12$ ). For WIN55,212-2 (5 $\mu \mathrm{g} / 0.5 \mu \mathrm{l})$ microinjected before conditioning (Pre-Cond WIN_5, $n=8$ ), before Ext1 (Pre-Ext1 WIN_5, $\bar{n}=9$ ), or immediately after Ext1 (Post-Ext1 WIN_5, $n=$ $9)$, repeated-measures ANOVA [treatment $\times$ days $(4 \times 4)$ ] did not reveal a significant difference between the groups in terms of their latency to enter the dark side of the box $\left(F_{(3,34)}<1\right.$; NS) (Fig. 2a). Also, there were no within-subject differences in the latency between the days $\left(F_{(1,34)}<1\right.$; NS), nor was there an interaction effect $\left(F_{(3,34)}<1\right.$; NS). Because of the apparent reduction in latency in the Pre-Ext1 WIN_5 group on the first extinction day, we analyzed the latency on Ext1 using one-way ANOVA, which did not reveal a significant effect $\left(F_{(3,34)}=1.43\right.$; NS).

Because dose-response issues may have been responsible for the failure of a microinjection of WIN55,212-2 into the BLA to affect latency, we examined the effects of other doses. Thus, the effect on latency was examined after microinjection of a lower [2.5 $\mu \mathrm{g} / 0.5 \mu \mathrm{l}$ (WIN_2.5), $n=7$ ] or a higher [10 $\mu \mathrm{g} / 0.5 \mu \mathrm{l}$ (WIN_10), $n=7$ ] dose of WIN55,212-2 into the BLA after Ext1. Repeated-measures ANOVA [treatment $\times$ days $(3 \times 4)$ ] did not reveal a significant difference between the groups in terms of their latency to enter the dark side of the box $\left(F_{(2,21)}<1\right.$; NS) (Fig. 2b). Also, there were no within-subject differences in the latency between the days $\left(F_{(1,21)}=1.81 ; \mathrm{NS}\right)$, nor was there an interaction effect $\left(F_{(2,21)}<1\right.$; NS). Thus, together with the results from Figure $2 a$, WIN55,212-2 microinjected into the BLA appears to have no effect on IA conditioning or extinction by itself.

A previous report (Chhatwal et al., 2005) showed that the $\mathrm{CB}_{1} / \mathrm{CB}_{2}$ receptor agonist WIN55,212-2, and an inhibitor of endocannabinoid reuptake and breakdown, AM404, have different effects on the extinction of contextual fear. Hence, we examined the effects of AM404 on the conditioning and extinction of IA.

Microinjecting vehicle into the BLA before conditioning, before Ext1, or immediately after Ext1 had no effect on the latency of rats to enter the dark side of the box $\left(F_{(2,10)}<1\right.$; NS). Consequently, all vehicle groups in the light-dark IA experiments involving AM404 were pooled for all analyses (vehicle; $n=13$ ).

For AM404 microinjected before conditioning (Pre-Cond $404, n=12$ ), before Ext1 (Pre-Ext1 404, $n=7$ ), or immediately after Ext1 (Post-Ext1 404, $n=10$ ), repeated-measures ANOVA [treatment $\times$ days $(4 \times 4)$ ] did not reveal a significant difference between the groups in terms of their latency to enter the dark side of the box $\left(F_{(3,38)}<1\right.$; NS) (Fig. $\left.2 c\right)$. Also, there were no withinsubject differences in the latency between the days $\left(F_{(1,38)}<1\right.$; $\mathrm{NS})$, nor was there an interaction effect $\left(F_{(3,38)}=1.157\right.$; NS). Because of the apparent reduction in latency in the Pre-Ext1 404 group on the first extinction day, we analyzed the latency on Ext1 using one-way ANOVA, which revealed a significant group effect $\left(F_{(3,38)}=4.04 ; p=0.014\right)$. Post hoc comparison showed a significant difference between the vehicle and the Pre-Ext1 404 group $(p=0.002)$ on Ext1, indicating a reduction in the latency to enter the dark side after microinjection of AM404 that recovered the following day. Using a higher dose of AM404 (800 ng/0.5 $\mu \mathrm{l}$ ) before the first extinction trial resulted in a similar effect, i.e., reduced latency to enter the dark side on Ext1 (vehicle, $118.03 \pm$ $4.1 \mathrm{~s}, n=7$; Pre-Ext1 404_800, $31.74 \pm 3.72 \mathrm{~s}, n=7 ; t_{(12)}=5.17$; $p<0.0001$ ), with no effect on Cond, Ext2, or Ext3 (data not shown). Thus, except for the transient effect on latency on Ext1, AM404 had no effect on IA conditioning or extinction.

Because the cannabinoid receptor agonist WIN55,212-2 microinjected into the BLA had no effect on IA conditioning or extinction, we next examined whether the $\mathrm{CB}_{1}$ receptor in the BLA is essential for IA conditioning or extinction. Hence, rats were microinjected with vehicle or the $\mathrm{CB}_{1}$ receptor antagonist AM251 before conditioning, before Ext1, or immediately after Ext1.

Microinjecting vehicle into the BLA before conditioning, before Ext1, or immediately after Ext1 had no effect on the latency of rats to enter the dark side of the box $\left(F_{(2,11)}<1\right.$; NS). Consequently, all vehicle groups for light-dark IA experiments involving AM251 were pooled for all analyses (vehicle; $n=14$ ).

For AM251 microinjected rats, repeated-measures ANOVA [treatment $\times$ days $(4 \times 4)$ ] revealed a significant difference between the groups in terms of their latency to enter the dark side of the box $\left(F_{(3,38)}=9.63 ; p<0.001\right)$ (Fig. $\left.2 d\right)$. Post hoc comparison unveiled a significant difference between the vehicle group and the groups microinjected with AM251 before conditioning (Pre- 

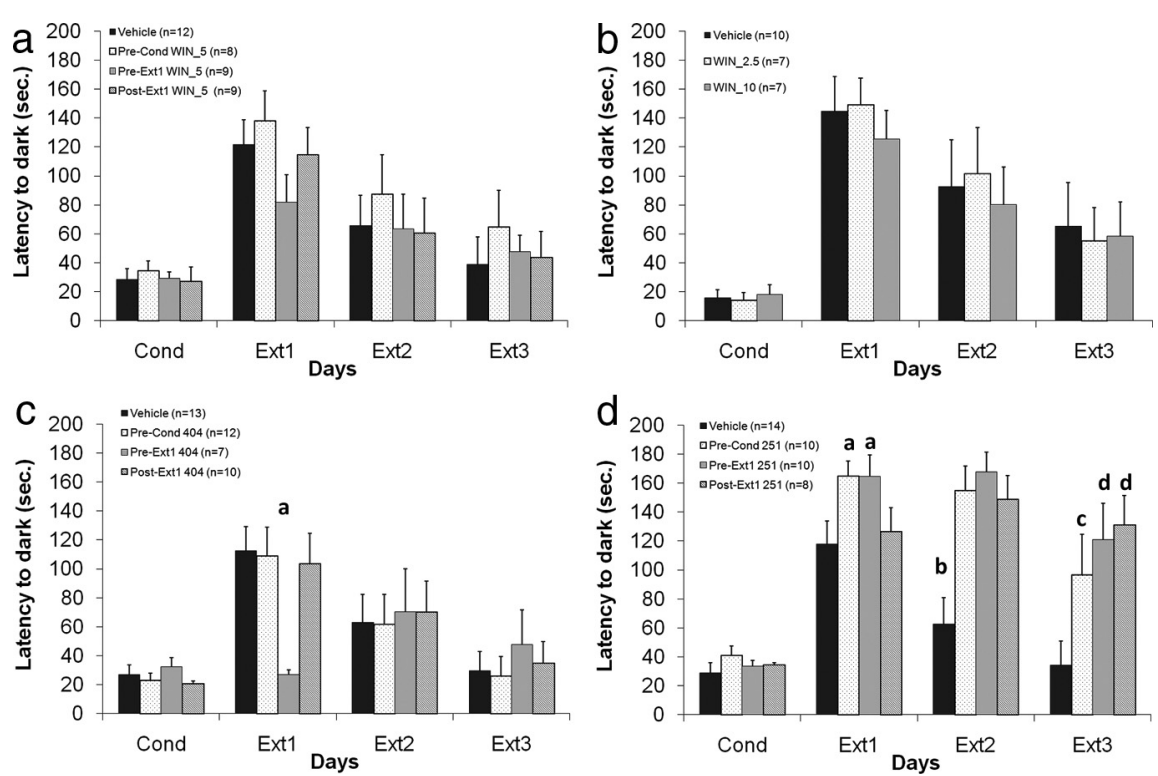

Figure 2. Cannabinoid receptor agonist WIN55,212-2 microinjected into the BLA has no effect on inhibitory avoidance conditioning or extinction. $\boldsymbol{a}$, Rats were microinjected into the BLA with vehicle $(n=12)$, with WIN55,212-2 (5 $\mu \mathrm{g} / 0.5 \mu \mathrm{l})$ before conditioning (Pre-Cond WIN_5, $n=8$ ), before the first extinction trial (Pre-Ext1 WIN_5, $n=9$ ), or immediately after that trial (Post-Ext1 WIN_5, $n=9$ ). There were no significant differences between the latencies of the groups. $\boldsymbol{b}$, Rats were microinjected into the BLA with vehicle $(n=10)$ or with a lower $(2.5 \mu \mathrm{g} / 0.5 \mu \mathrm{l}$; WIN_2.5, $n=7)$ or a higher $(10 \mu \mathrm{g} / 0.5 \mu \mathrm{l}$; WIN_10, $n=7)$ dose of WIN55,212-2 immediately after Ext1. There were no significant differences between the latencies of the groups. $\boldsymbol{c}$, Rats were microinjected into the BLA with vehicle $(n=13)$ or with AM404 (200 ng/0.5 $\mu$ l) before conditioning (Pre-Cond 404, $n=12$ ), before the first extinction trial (Pre-Ext1 404, $n=7$ ), or immediately after that trial (Post-Ext1 404, $n=10$ ). The latency of the Pre-Ext1 404 group was significantly shorter than that of the vehicle group on the first extinction day (Ext1, ${ }_{p} p<0.01$ ) (for details, see Results). $\boldsymbol{d}$, Rats were microinjected into the BLA with vehicle $(n=14)$ or AM251 ( $6 \mathrm{ng} / 0.5 \mu l)$ before conditioning (Pre-Cond $251, n=10$ ), before the first extinction trial (Pre-Ext1 251, $n=10$ ), or immediately after that trial (Post-Ext1 251, $n=8$ ). The latencies of all the AM251-injected groups were significantly longer than that of the vehicle group, indicating enhancement of inhibitory avoidance acquisition and/or consolidation and impaired extinction. (Ext1, ${ }^{a} p<0.05$, vehicle different from Pre-Cond 251 and Pre-Ext1 groups; Ext2, ${ }^{b} p<0.001$, vehicle different from all the groups; Ext3, ${ }^{c} p<0.05$, vehicle different from Pre-Cond $251{ }^{d} p<0.01$, vehicle different from Pre-Ext1 251 and Post-Ext1 251 groups).

Cond 251, $n=10 ; p<0.001)$, before Ext1 (Pre-Ext1 251, $n=10$; $p<0.001$ ), or after Ext1 (Post-Ext1 251, $n=8 ; p=0.001$ ).

One-way ANOVA applied on each day revealed that the significant main effect stemmed from a difference in latency between the AM251-treated groups and the vehicle group throughout the extinction days $\left(\operatorname{Ext} 1, F_{(3,38)}=3.12, p=0.037\right.$; Ext2, $\left.F_{(3,38)}=9.44, p<0.001 ; \operatorname{Ext} 3, F_{(3,38)}=4.5, p=0.008\right)$ but not on the conditioning day. Post hoc comparison revealed a significant difference between the vehicle group and the PreCond 251 and Pre-Ext1 251 groups $(p=0.02)$ on Ext1, and between the vehicle group and all the treatment groups on Ext2 $(p<0.001)$ and Ext3 (Pre-Cond 251, $p=0.039$; Pre-Ext1 251, $p=0.005$; Post-Ext1 251, $p=0.004)$.

Thus, AM251 microinjected before conditioning enhanced IA acquisition and/or consolidation, as indicated by a higher latency to enter the dark side of the box on Ext1, and impaired extinction, as indicated by a higher latency to enter the dark side on Ext 2 and Ext3. When AM251 was microinjected before the first extinction trial, it enhanced IA retrieval and impaired extinction. Finally, AM251 microinjected after Ext1 impaired the consolidation of IA extinction, as shown by the increased latency on Ext2 and Ext3 (but not before microinjection on Ext1). Repeated-measures ANOVA also revealed significant within-subject differences in the latency between the days $\left(F_{(1,38)}=22.09 ; p<0.001\right)$ and a significant interaction effect $\left(F_{(3,38)}=4.92 ; p=0.005\right)$. Hence, the cannabinoid receptor in the BLA is crucially involved in the conditioning and extinction of IA.

\section{Cannabinoid receptor agonist WIN55,212-2 microinjected into the BLA blocks the effects of stress on inhibitory avoidance conditioning and extinction}

To examine the effects of exposure to a stressful experience on the conditioning and extinction of IA, rats were exposed to the EP stress before conditioning, before Ext1, or immediately after Ext1. To examine whether cannabinoid receptor agonist would reverse the effects of stress on IA conditioning and extinction, WIN55,212-2 was microinjected into the BLA immediately before placing the rats on the EP (WIN+EP groups).

Before conditioning, rats were microinjected with vehicle $(n=12)$, placed on the EP for 30 min (EP Pre-Cond, $n=9$ ), or microinjected with WIN55,212-2 (5 $\mu \mathrm{g} / 0.5 \mu \mathrm{l})$ and immediately afterward placed on the EP for $30 \mathrm{~min}$ (WIN_5+EP, $n=7)$. Repeated-measures ANOVA [treatment $\times$ days $(3 \times 4)]$ revealed a significant difference between the groups in terms of their latency to enter the dark side of the box $\left(F_{(2,25)}=4.57 ; p=0.02\right)$ (Fig. 3a). Post hoc comparison unveiled a significant difference between the vehicle and the EP Pre-Cond group $(p=0.006)$.

One-way ANOVA applied on the different days revealed that the significant main effect stemmed from a difference in latency between the groups on Ext1 $\left(F_{(2,25)}=4.184 ; p=0.027\right)$ but not afterward. Post hoc comparison showed significantly increased latency in the EP group compared with the vehicle group $(p=0.008)$. There were no within-subject differences in the latency between the days $\left(F_{(1,25)}<1\right.$; NS), nor was there an interaction effect $\left(F_{(2,25)}=1.48\right.$; NS). Thus, exposure to the EP stressor before conditioning enhanced IA acquisition and/or consolidation on Ext1, and microinjecting WIN55,212-2 into the BLA before exposure to the EP reversed the effects of the stressor on IA conditioning, because no significant differences were observed between the vehicle and WIN_5+EP group throughout the days of the experiment.

The experiment was then repeated on another set of rats with stress exposure and drug administration placed before the first extinction day. Before Ext1, rats were microinjected with vehicle $(n=12)$, placed on the EP for $30 \mathrm{~min}$ (EP Pre-Ext1, $n=9$ ), or microinjected with WIN55,212-2 $(5 \mu \mathrm{g} / 0.5 \mu \mathrm{l})$ and immediately afterward placed on the EP for 30 min (WIN_5+EP, $n=10$ ). Repeated-measures ANOVA [treatment $\times$ days $(3 \times 4)$ ] did not reveal a significant difference between the groups in terms of their latency to enter the dark side of the box $\left(F_{(2,28)}=1.04\right.$; NS) (Fig. $3 b$ ). Also, there were no within-subject differences in the latency between the days $\left(F_{(1,28)}=1\right.$; NS), nor was there an interaction effect $\left(F_{(2,28)}=1.04 ; \mathrm{NS}\right)$. However, rats that were placed on the EP avoided entering the dark side on Ext1 altogether (all rats reached the maximum latency of $180 \mathrm{~s}$ ). Thus, using one-way ANOVA on the different days, we found a significant effect on latency on $\operatorname{Ext1}\left(F_{(2,28)}=4.81 ; p=0.017\right)$. Post hoc comparisons revealed significantly increased latency in the EP group compared 
with the vehicle $(p=0.022)$ and WIN_5+EP $(p=0.007)$ groups on the first extinction day. Thus, exposure to the EP stressor before the first extinction trial enhanced IA retrieval and microinjecting WIN55,212-2 into the BLA before exposure to the EP blocked the effects of the stressor on retrieval, because no significant differences were observed between the vehicle and WIN_5+EP groups throughout the days of the experiment.

The experiment was then repeated again on a third set of rats with stress exposure and drug administration placed after the first extinction day. After Ext1, rats were microinjected with vehicle $(n=$ 14 ), placed on the EP for $30 \mathrm{~min}$ (EP PreExt1, $n=8)$, or microinjected with WIN55,212-2 (5 $\mu \mathrm{g} / 0.5 \mu \mathrm{l})$ and immediately afterward placed on the EP for 30 min (WIN_5+EP, $n=8$ ). Repeatedmeasures ANOVA [treatment $\times$ days $(3 \times 4)$ ] did not reveal a significant difference between the groups in terms of their latency to enter the dark side of the box $\left(F_{(2,27)}=1.86\right.$; NS) (Fig. $\left.3 c\right)$. Also, there were no within-subject differences in latency between the days $\left(F_{(1,27)}<1\right.$; NS), nor was there an interaction effect $\left(F_{(2,27)}=1.37\right.$; NS $)$. However, rats that were placed on the EP showed increased latency to enter the dark side of the box on Ext2, and, using one-way ANOVA on the different days, we found a significant effect on the latency on Ext2 $\left(F_{(2,27)}=3.4\right.$; $p=0.048)$. Post hoc comparisons revealed significantly increased latency in the EP group compared with the vehicle $(p=$ $0.019)$ and WIN_5+EP $(p=0.05)$ groups.

Thus, exposure to the EP stressor after the first extinction trial disrupted the consolidation of extinction, and microinjecting WIN55,212-2 before exposure to the EP reversed the impairing effects of the stressor, because no significant differences were observed between the vehicle and WIN_5+EP groups on the second and third extinction days.

Next we examined whether a lower dose of WIN55,212-2 (2.5 $\mu \mathrm{g} / 0.5 \mu \mathrm{l}) \mathrm{mi}-$ croinjected into the BLA after Ext1 would also block the impairing effects of the stressor on the consolidation of IA extinction. After Ext1, rats were microinjected with vehicle $(n=$ 8 ), placed on the EP for $30 \mathrm{~min}$ (EP Post-Ext1, $n=8$ ), or microinjected with a lower dose of WIN55,212-2 and immediately afterward placed on the EP for 30 min (WIN_2.5+EP, $n=8)$. Repeated-measures ANOVA [treatment $\times$ days $(3 \times 4)$ ] did not reveal a significant difference between the groups in terms of their latency to enter the dark side of the box $\left(F_{(2,21)}=1.03\right.$; NS) (Fig. $3 d$ ). Also, there were no within-subject differences in latency between the days $\left(F_{(1,21)}=2.7\right.$; NS), nor was there an stressor on IA extinction.
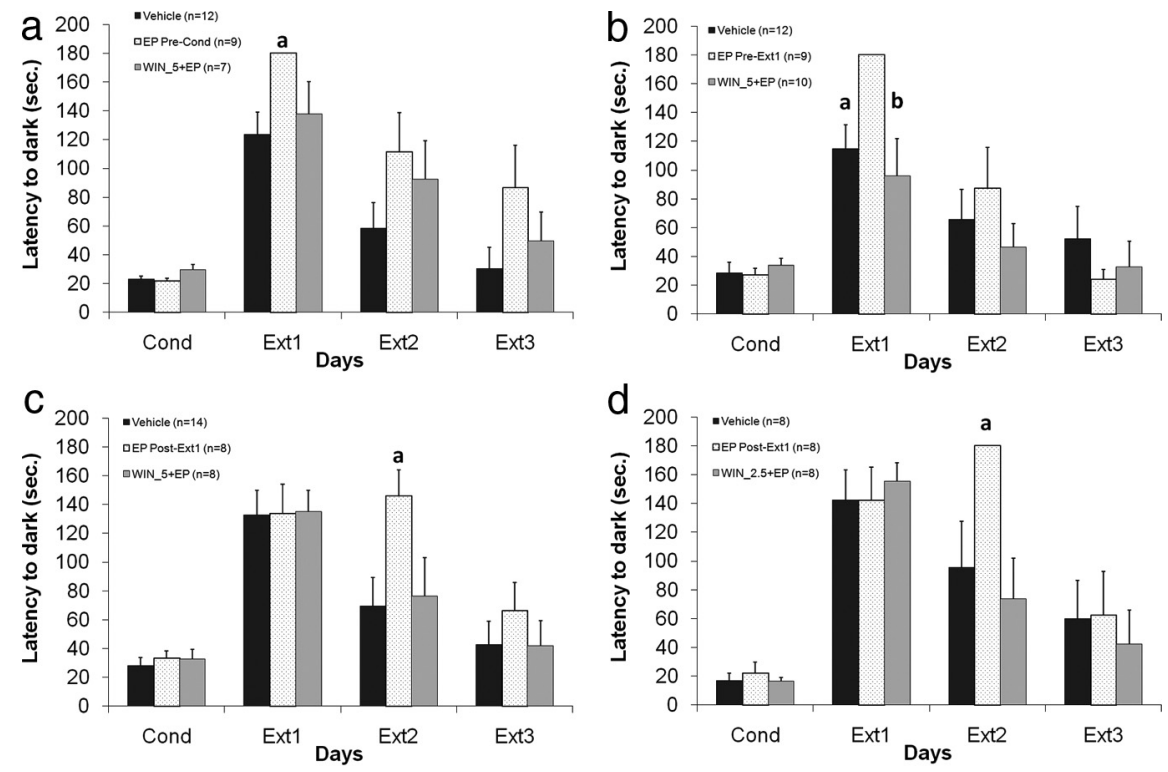

Figure 3. Cannabinoid receptor agonist WIN55,212-2 blocks the effects of EP stress on IA conditioning and extinction. $\boldsymbol{a}$, Before conditioning, rats were microinjected with vehicle $(n=12)$, placed on the EP (EP Pre-Cond, $n=9)$, or microinjected with WIN55,212-2 $(5 \mu \mathrm{g} / 0.5 \mu \mathrm{l})$ and immediately afterward placed on the EP (WIN_5 +EP, $n=7)$. The EP Pre-Cond group showed a significantly increased latency to enter the dark side on the first extinction day compared with the vehicle group (Ext1, ${ }^{a} p<0.01$ ). Thus, WIN55,212-2 administered into the BLA before stressor exposure reversed the enhancing effect of the stressor on IA acquisition and/or consolidation. $\boldsymbol{b}$, Before the first extinction trial, rats were microinjected with vehicle $(n=12)$, placed on the EP (EP Pre-Ext1, $n=9$ ), or microinjected with WIN55,212-2 $(5 \mu \mathrm{g} / 0.5 \mu \mathrm{l})$ and immediately afterward placed on the EP (WIN_5+EP, $n=10$ ). The EP Pre-Ext1 group showed a significantly increased latency to enter the dark side on the first extinction day (Ext1, ${ }^{a} p<0.05$, EP differs from vehicle; $p<<0.01$, EP differs from WIN_5+EP). Thus, WIN55,212-2 administered into the BLA before stressor exposure reversed the enhancing effect of the stressor on IA retrieval. $c$, After the first extinction trial, rats were microinjected with vehicle $(n=14)$, placed on the EP (EP Post-Ext1, $n=8)$, or microinjected with WIN55,212-2 (5 $\mu \mathrm{g} / 0.5 \mu \mathrm{l})$ and immediately afterward placed on the EP (WIN $5+E P, n=8$ ). The EP Post-Ext1 group showed a significantly increased latency to enter the dark side on the second extinction day compared with the other groups (Ext2, ${ }^{a} p<0.05$ ). Thus, WIN55,212-2 administered into the BLA before stressor exposure reversed the disrupting effect of the stressor on IA extinction. $\boldsymbol{d}$, After the first extinction trial, rats were microinjected with vehicle $(n=8)$, placed on the EP (EP Post-Ext1, $n=8)$, or microinjected with a low dose of WIN55,212-2 $(2.5 \mu \mathrm{g} / 0.5 \mu \mathrm{l})$ and immediately afterward placed on the EP (WIN_2.5 + EP, $n=8)$. The EP Post-Ext1 group showed a significantly increased latency to enter the dark side on the second extinction day (Ext2, ${ }^{a} p<0.01$, EP Post-Ext1 differs from WIN_2.5+EP). Thus, a lower dose of WIN55,212-2 administered into the BLA before stressor exposure also reversed the disrupting effect of the stressor on IA extinction. $\boldsymbol{e}$, After the first extinction trial, rats were intraperitoneally injected with vehicle $(n=9)$, placed on the EP (EP Post-Ext1, $n=8)$, intraperitoneally injected with WIN $(0.25 \mathrm{mg} / \mathrm{kg} ;$ WIN IP, $n=8)$, or intraperitoneally injected with WIN and immediately afterward placed on the EP (WIN IP $+E P, n=7)$. The EP Post-Ext1 group showed a significantly increased latency to enter the dark side on the second extinction day compared with all the other groups (Ext2, ${ }^{a} p<$ 0.01). Thus, intraperitoneal administration of WIN55,212-2 before stressor exposure also reversed the disrupting effect of the

interaction effect $\left(F_{(2,21)}<1\right.$; NS). However, rats that were placed on the EP showed increased latency to enter the dark side of the box on Ext2 (i.e., all EP Post-Ext1 rats reached the maximum latency of $180 \mathrm{~s}$ ). Thus, using one-way ANOVA on the different days, we found a significant effect on the latency on Ext2 $\left(F_{(2,21)}=4.42 ; p=0.027\right)$. Post hoc comparisons revealed significantly increased latency in the EP group compared with the WIN_2.5+EP group $(p=0.009)$ and a marginally significant difference compared with the vehicle group ( $p=0.061)$. Thus, 
Table 1. The effects of cannabinoid receptor agonists and antagonist microinjected into the BLA on locomotion and anxiety in the open-field test

\begin{tabular}{lccrr}
\hline & Vehicle $(n=6)$ & AM404 $(n=6)$ & WIN55,212-2 $(n=6)$ & AM251 $(n=6)$ \\
\hline Time in center $(s)$ & $7.83 \pm 1.25$ & $6.33 \pm 1.31$ & $4.66 \pm 1.08$ & $4.5 \pm 1.28$ \\
Time in periphery $(s)$ & $292.16 \pm 1.25$ & $293.66 \pm 1.31$ & $295.33 \pm 1.08$ & $22 \pm 1.69$ \\
Number of rearing events & $20.33 \pm 1.74$ & $21.66 \pm 2.03$ & $1.25 .5 \pm 1.28$ \\
Distance covered (s) & $1758.33 \pm 114.32$ & $1916.66 \pm 158.46$ & $1675 \pm 107.04$ & $19.16 \pm 2.10$ \\
\hline
\end{tabular}

Rats microinjected into the BLA with the $\mathrm{CB}_{1}$ receptor antagonist (AM251, $n=6$ ), one of the agonists (WIN55,212-2 or AM404, $n=6$ each), or vehicle ( $n=6$ ) showed no differences in any of the parameters measured in the open-field test.

microinjecting a lower dose of WIN55,212-2 into the BLA before exposure to the EP also reversed the impairing effects of the stressor on the consolidation of extinction.

Finally, we were interested in investigating whether the same effects would be seen after systemic treatment with WIN55,212-2 (0.25 mg/kg, i.p.). Hence, immediately after Ext1, rats were intraperitoneally injected with vehicle (Vehicle IP, $n=9$ ), placed on the EP for 30 min (EP Post-Ext1, $n=8)$, intraperitoneally injected with WIN55,212-2 (WIN IP, $n=8$ ), or intraperitoneally injected with WIN55,212-2 and immediately afterward placed on the EP for $30 \mathrm{~min}$ (WIN IP $+\mathrm{EP}, n=$ $7)$. Repeated-measures ANOVA [treatment $\times$ days $(3 \times 4)$ ] revealed a strong trend in terms of the latency to enter the dark side of the box $\left(F_{(3,28)}=2.61 ; p=0.07\right)$ (Fig. $3 e$ ). One-way ANOVA applied on the different days revealed a significant difference in latency between the groups on Ext2 $\left(F_{(3,28)}=\right.$ 5.94; $p=0.003$ ). Post hoc comparison showed significantly increased latency in the EP group compared with the other groups $(p=0.002)$. Thus, systemic administration of WIN55,212-2 before exposure to the EP also reversed the impairing effects of the stressor on the consolidation of extinction. Repeated-measures ANOVA also revealed a significant interaction effect $\left(F_{(3,28)}=5.68 ; p=0.004\right)$ but no within-subject differences in latency between the days $\left(F_{(1,28)}=1.4 ; \mathrm{NS}\right)$.

\section{The effects of the different manipulations on anxiety and sensorimotor parameters}

Next, we performed two types of control experiments (the openfield and pain sensitivity tests) to exclude the possibility that the effects of the drugs on IA acquisition, consolidation, or extinction were caused by sensorimotor deficits or by increased anxiety under the experimental conditions used. Hence, rats were microinjected into the BLA with the $\mathrm{CB}_{1}$ receptor antagonist (AM251, $n=6 ; 6 \mathrm{ng} / 0.5 \mu \mathrm{l})$, agonists [WIN_5, $n=6(5 \mu \mathrm{g} / 0.5 \mu \mathrm{l})$ and AM404, $n=6(200 \mathrm{ng} / 0.5 \mu \mathrm{l})]$, or vehicle $(n=6)$ and then tested in the open-field arena and in the pain sensitivity test. One-way ANOVA did not reveal a significant difference in any of the parameters measured in the open-field test (Table 1), namely, time spent in the center $\left(F_{(3,20)}=1.65\right.$; NS), time spent in the periphery $\left(F_{(3,20)}=2.8 ; \mathrm{NS}\right)$, number of rearing events $\left(F_{(3,20)}<1\right.$; NS), or the distance covered $\left(F_{(3,20)}=2.44 ; \mathrm{NS}\right)$. Also, ANOVA did not reveal significant differences in pain sensitivity $\left(F_{(3,20)}<1\right.$; NS) (Table 2).

Although WIN55,212-2 microinjected into the BLA had no effect on locomotion, anxiety, or pain sensitivity by itself, the combination of WIN55,212-2 and the EP could conceivably have a different effect on those parameters than either component alone. Hence, experiments were undertaken in which the rats were microinjected into the BLA with vehicle $(n=6)$, placed on the $\operatorname{EP}(n=5)$, or microinjected with WIN55,212-2 and placed on the EP (WIN_5+EP, $n=6$ ) and then tested in the open-field arena and in the pain sensitivity test. In the open field, one-way ANOVA did not reveal a significant difference between the
Table 2. The effects of cannabinoid receptor agonists and antagonist microinjected into the BLA on pain sensitivity

\begin{tabular}{lllll}
\hline & $\begin{array}{l}\text { Vehicle } \\
(n=6)\end{array}$ & $\begin{array}{l}\text { AM404 } \\
(n=6)\end{array}$ & $\begin{array}{l}\text { WIN55,212-2 } \\
(n=6)\end{array}$ & $\begin{array}{l}\text { AM251 } \\
(n=6)\end{array}$ \\
\hline $\begin{array}{c}\text { Pain threshold for foot } \\
\text { shock (mA) }\end{array}$ & $0.36 \pm 0.04$ & $0.31 \pm 0.03$ & $0.30 \pm 0.01$ & $0.34 \pm 0.03$ \\
\hline
\end{tabular}

Rats microinjected into the $B L A$ with the $\mathrm{CB}_{1}$ receptor antagonist ( $A M 251, n=6$ ), one of the agonists (WIN55,212-2 or AM404, $n=6$ each), or vehicle $(n=6)$ showed similar pain sensitivity responses to electric footshock.

Table 3. The effects of WIN 55,212-2 and the EP on locomotion and anxiety in the open-field test

\begin{tabular}{lccr}
\hline & $\begin{array}{l}\text { Vehicle } \\
(n=6)\end{array}$ & $\begin{array}{l}\text { EP } \\
(n=5)\end{array}$ & \multicolumn{1}{c}{ WIN55,212-2+ } \\
& \multicolumn{1}{c}{ EP $(n=6)$} \\
\hline Time in center (s) & $9.5 \pm 0.76$ & $7.8 \pm 4.18$ & $5.5 \pm 1.91$ \\
Time in periphery (s) & $290.5 \pm 0.76$ & $292.2 \pm 4.18$ & $294.5 \pm 1.91$ \\
Number of rearing events & $19.16 \pm 1.25$ & $10.4 \pm 2.28^{*}$ & $12.83 \pm 1.1^{* *}$ \\
Distance covered (s) & $1525 \pm 163.17$ & $1080 \pm 180.62$ & $1258.33 \pm 84.07$
\end{tabular}

Rats placed on the EP $(n=5)$ showed increased rearing in the open-field test compared with groups that received a microinjection of vehicle $(n=6)$ or WIN55,212-2 before being placed on the platform (WIN $5+E P ; n=6)\left({ }^{*} p<\right.$ 0.05 , vehicle group differs from WIN_5+EP group; ${ }^{* *} p<0.01$, vehicle group differs from EP group).

\section{Table 4. The effects of WIN55,212-2 and the EP on pain sensitivity}

\begin{tabular}{llll}
\hline & $\begin{array}{l}\text { Vehicle } \\
(n=6)\end{array}$ & $\begin{array}{l}\text { EP } \\
(n=5)\end{array}$ & $\begin{array}{l}\text { EP+WIN55,212-2 } \\
(n=6)\end{array}$ \\
\hline $\begin{array}{c}\text { Pain threshold for } \\
\text { foot shock }(\mathrm{mA})\end{array}$ & $0.26 \pm 0.01$ & $0.24 \pm 0.01$ & $0.24 \pm 0.01$ \\
\hline
\end{tabular}

Rats microinjected into the BLA with vehicle $(n=6)$, placed on the EP $(n=5)$, or microinjected with WIN55,212-2 and placed on the EP (WIN_5 + EP, $n=6$ ) showed similar pain sensitivity responses to electric footshock.

groups in terms of time spent in the center $\left(F_{(2,14)}<1\right.$; NS), time spent in the periphery $\left(F_{(2,14)}<1\right.$; NS), or the distance covered $\left(F_{(2,14)}=2.17\right.$; NS) (Table 3$)$. However, a significant difference was found between the groups in terms of the number of rearing events $\left(F_{(2,14)}=7.74 ; p=0.005\right)$. Post hoc comparisons revealed that the vehicle group reared significantly more times than the EP $(p=0.002)$ and the WIN_5+EP $(p=0.013)$ groups. Rearing behavior characterizes individual differences in reactivity to novelty, and, thus, more frequent rearing may indicate greater novelty seeking behavior (i.e., less anxiety) (Thiel et al., 1999). The EP group showed a reduced number of rearing events and a trend toward a reduced distance covered in the open-field test compared with the control group, thus suggesting an increased stress level that may have contributed to the enhanced IA acquisition or consolidation and disrupted extinction shown in the previous figures.

Finally, one-way ANOVA did not reveal significant differences in pain sensitivity $\left(F_{(2,14)}<1\right.$; NS) (Table 4).

WIN55,212-2 microinjected into the BLA or administered intraperitoneally reduces stress-induced increases in corticosterone levels

Because it has been suggested that the augmentation of endocannabinoid signaling can suppress stress-responsive systems 

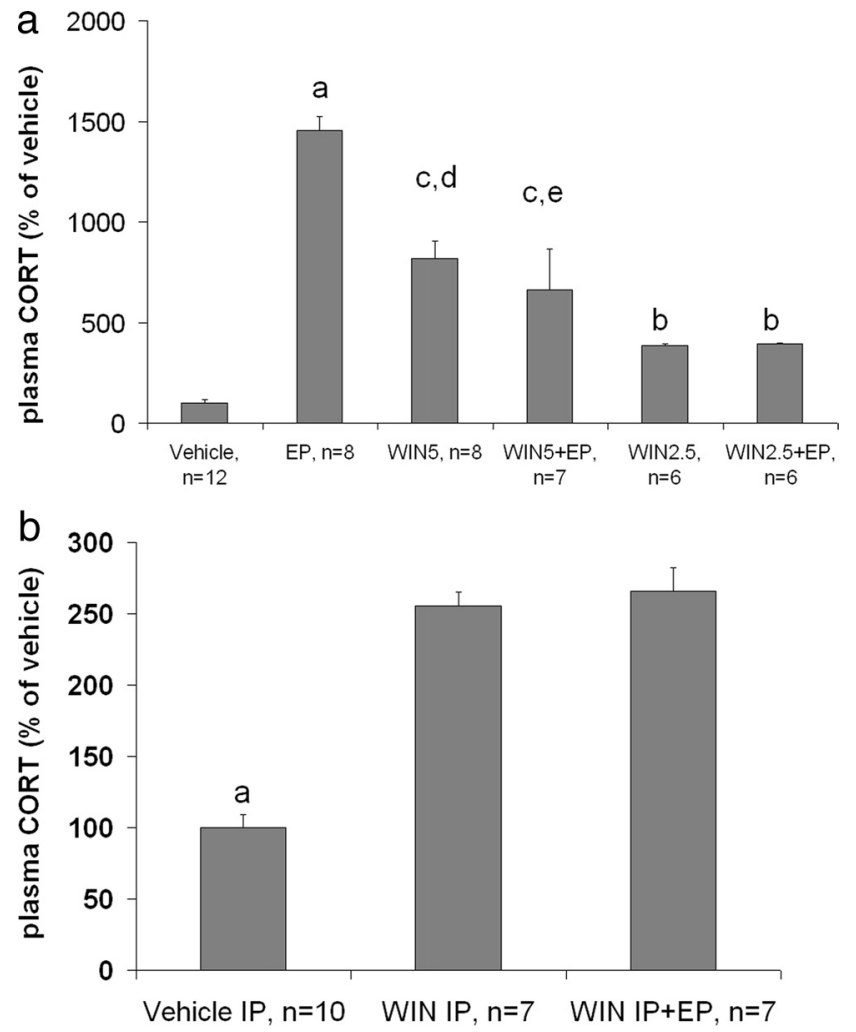

Figure 4. The effects of the cannabinoid receptor agonist WIN55,212-2 and EP stress on CORT levels. $\boldsymbol{a}$, CORT levels were measured in rats microinjected with vehicle into the BLA (vehicle, $n=12)$, placed on the EP $(n=8)$, microinjected with WIN55,212-2 (5 $\mu \mathrm{g} / 0.5$ $\mu l)$ into the BLA (WIN_5, $n=8)$, microinjected with WIN55,212-2 $(5 \mu \mathrm{g} / 0.5 \mu l)$ into the BLA and placed on the EP (WIN_5+EP, $n=7$ ), microinjected with a lower dose of WIN55,212-2 $(2.5 \mu \mathrm{g} / 0.5 \mu \mathrm{l})$ into the BLA (WIN_2.5, $n=6)$, or microinjected with the lower dose of WIN55,212-2 and placed on the EP (WIN_2.5 +EP, $n=6$ ). Data represent the means \pm SEM expressed as a percentage of the CORT values of the vehicle animals (CORT levels in the vehicle group, $95.52 \pm 16.7 \mathrm{ng} / \mathrm{ml})\left({ }^{a} p<0.001\right.$, EP group differs from all other groups; ${ }^{b} p<0.05$ and ${ }^{c} p<0.001$, vehicle group differs from all other groups; ${ }^{d} p<0.01$, WIN_5 group differs from WIN_2.5 and WIN_2.5+EP groups; ${ }^{e} p<0.05$, WIN_5+EP group differs from WIN_2.5 and WIN_2.5+EP groups). $\boldsymbol{b}$, CORT levels were measured in rats injected intraperitoneally with vehicle (Vehicle $\mathbb{P}, n=10$ ), WIN55,212-2 (WIN IP, $n=7$ ), or injected with WIN55,212-2 intraperitoneally and placed on the EP (WIN IP + EP, $n=7)$. Data represent the means \pm SEM expressed as a percentage of the CORT values of the vehicle animals (CORT levels in the vehicle group, $381.01 \pm$ $64.39 \mathrm{ng} / \mathrm{ml})\left({ }^{a} p<0.001\right.$, vehicle group differs from all other groups).

(Patel et al., 2004; Cota, 2008; Steiner and Wotjak, 2008), we sought to examine whether WIN55,212-2 given in conjunction with EP had a different effect on CORT levels than did exposure to the stressor alone.

In the first CORT experiment, rats were microinjected with vehicle to the BLA (vehicle, $n=12)$, placed on the EP $(n=8)$, microinjected with WIN55,212-2 (5 $\mu \mathrm{g} / 0.5 \mu \mathrm{l})$ into the BLA (WIN_5, $n=8)$, microinjected with WIN55,212-2 (5 $\mu \mathrm{g} / 0.5$ $\mu \mathrm{l})$ and placed on the EP (WIN_5 +EP, $n=7$ ), microinjected with a lower dose of WIN55,212-2 $(2.5 \mu \mathrm{g} / 0.5 \mu \mathrm{l})$ into the BLA (WIN_2.5, $n=6$ ), or microinjected with the lower dose of WIN55,212-2 and placed on the EP (WIN_2.5+EP, $n=6$ ).

Thirty minutes after microinjection (vehicle and WIN groups) or immediately after the EP (EP and WIN+EP groups), trunk blood was collected for CORT measurement. One-way ANOVA on CORT levels unveiled a significant difference between the groups $\left(F_{(5,41)}=32.7 ; p<0.001\right)$ (Fig. $4 a$ ). Post hoc comparisons revealed that rats that were exposed to the EP in the absence of previous WIN microinjection, i.e., the EP group, showed the highest CORT levels when compared with all the groups $(p<0.001)$. The vehicle group showed the lowest CORT levels and was significantly different from all the groups (WIN_5 and WIN_5+EP, $p<0.001$; WIN_2.5 and WIN_2.5+EP, $p<0.05)$. Also, the WIN_2.5 and WIN_2.5+EP groups showed significantly lower CORT levels than the WIN_5 $(p<0.01)$ and WIN_5+EP groups $(p<$ $0.05)$. Hence, WIN55,212-2 microinjection into the BLA (2.5 $\mu \mathrm{g} / 0.5 \mu \mathrm{l}$ or $5 \mu \mathrm{g} / 0.5 \mu \mathrm{l}$ ) in itself increased CORT levels compared with those of the vehicle group, but it reduced CORT levels in rats that were exposed to the EP stress when compared with rats exposed to the EP without WIN microinjection. Furthermore, although both WIN doses reversed the stressinduced increase in CORT levels, the effect was dose dependent, because a lower dose of WIN resulted in less CORT activation than did the higher dose of WIN.

In the second CORT experiment, rats were injected intraperitoneally with vehicle (Vehicle IP, $n=10$ ) or WIN55,212-2 (WIN IP, $n=7)$, or injected with WIN55,212-2 and placed on the EP (WIN IP+EP, $n=7$ ).

Thirty minutes after injection (vehicle and WIN groups) or immediately after the EP (WIN+EP group), trunk blood was collected for CORT measurement. It seems that the injection of the vehicle intraperitoneally is stressful by itself because the intraperitoneal vehicle group showed relatively enhanced CORT levels (CORT levels in the vehicle group, $381.01 \pm$ $64.39 \mathrm{ng} / \mathrm{ml})$. Nevertheless, one-way ANOVA on CORT levels unveiled a significant difference between the groups $\left(F_{(2,21)}=\right.$ 39.11; $p<0.001$ ) (Fig. 4b). Post hoc comparisons revealed that the vehicle rats showed significantly lower CORT levels than the WIN IP and WIN IP+EP groups $(p<0.001)$. Hence, WIN55,212-2 injected intraperitoneally in itself increased CORT levels compared with those of the vehicle group, but it reduced CORT levels in rats that were exposed to the EP stress when compared with rats exposed to the EP without WIN injection (EP) (shown in Fig. 4a).

Finally, we examined whether the effects of AM251 microinjected into the BLA on IA conditioning and extinction are associated with alterations in CORT levels. $t$ test unveiled a significant increase in CORT levels in rats microinjected with AM251 into the BLA [AM251 BLA, $n=7$; plasma CORT levels ( $\%$ of vehicle), $199.8 \pm 40.8 \mathrm{ng} / \mathrm{ml}]$ compared with the vehicle group (Vehicle BLA, $n=10$; CORT levels, $100 \pm 25.72 \mathrm{ng} / \mathrm{ml})\left(t_{(15)}=2.16 ; p=\right.$ 0.047).

\section{Discussion}

The main finding of the present study is that cannabinoid receptor activation in the BLA reverses the enhancing effects of environmental stress on IA conditioning and its impairing effects on extinction. We also find that WIN55,212-2 microinjected into the BLA inhibits stress-induced corticosterone elevation, thus suggesting that the reversal of the effects of stress on memory caused by cannabinoid activation in the BLA may be associated with influences on the HPA axis. Furthermore, the results show the crucial involvement of the $\mathrm{CB}_{1}$ receptor in the BLA in the extinction of avoidance behavior because the $\mathrm{CB}_{1}$ receptor antagonist impairs IA extinction. The control experiments demonstrate that the effects of WIN55,212-2 cannot be attributed to sensorimotor deficits, because these parameters seemed unchanged by WIN55,212-2 microinjected into the BLA. Together, these findings suggest that the BLA could be an important neural substrate relevant to the effects of cannabi- 
noids on emotional responses and that cannabinoids may have a potential therapeutic value in the treatment of fear- and stress-related disorders.

\section{The effects of $\mathrm{CB}_{1}$ receptor antagonist AM251 on inhibitory avoidance learning}

Administration of the $\mathrm{CB}_{1}$ receptor antagonist into the BLA before conditioning or before/after the first extinction trial potentiates the aversive response or blocks extinction of IA. Indeed, the importance of $\mathrm{CB}_{1}$ receptors in the extinction of aversive memories has been substantiated by several groups in different behavioral paradigms using systemic administration. $\mathrm{CB}_{1}$ receptor antagonists were found to impair extinction in fear-related (Marsicano et al., 2002; Suzuki et al., 2004; Chhatwal et al., 2005; Reich et al., 2008) and non-fear-related paradigms (Varvel and Lichtman, 2002), with no effect on appetitively motivated learning tasks (Hölter et al., 2005; Niyuhire et al., 2007; Harloe et al., 2008). Reich et al. (2008) found that administrating AM251 enhances acquisition of freezing behavior and impairs extinction in trace and delay pavlovian fear conditioning. However, several studies did not find the $\mathrm{CB}_{1}$ receptor antagonist to have any effect on memory acquisition or consolidation (Marsicano et al., 2002; Suzuki et al., 2004; De Oliveira Alvares et al., 2008). Recently, it has been suggested that the endocannabinoid system prevents the expression of inappropriate generalized and learned responses during aversive learning and retention (Reich et al., 2008), thus, possibly explaining the enhancing effects of the $\mathrm{CB}_{1}$ receptor antagonist on IA learning and its impairing effects on extinction.

Memory retrieval is thought to activate a second memory consolidation cascade (i.e., reconsolidation) or it may initiate the opposite process of extinction (Nader et al., 2000; Sara, 2000; Dudai, 2002; Alberini, 2005). Reconsolidation acts to stabilize, whereas extinction tends to weaken, the expression of the original memory. It has been suggested that, after retrieval, there is a brief time window for reconsolidation, whereas extinction only occurs after prolonged reexposure, and that the process that prevails is determined (at least partly) by the duration of the reexposure (Suzuki et al., 2004). Here, the latencies of the control rats to enter the dark side decreased over repeated tests, thus supporting the extinction process. Accordingly, we suggest that AM251 microinjected into the BLA impairs IA extinction rather than facilitates reconsolidation.

\section{The effects of cannabinoid receptor agonists WIN55,212-2 and AM404 on inhibitory avoidance learning}

WIN55,212-2, in doses ranging from 2.5 to $10 \mu \mathrm{g} / 0.5 \mu \mathrm{l}$, administered into the BLA has no effect on IA conditioning or on extinction kinetics. AM404 microinjected before the first extinction trial reduces the latency to enter the dark side on Ext1, with latency recovering the following day. Thus, the drug may elicit a general decrease in the inhibitory response that temporarily affects the rats' latency. Chhatwal et al. (2005) have shown that AM404 facilitates the retention of extinction of conditioned fear, whereas WIN55,212-2 has no effect. However, Pamplona et al. (2006) found that WIN55,212-2 facilitates the extinction of both contextual fear memory and a reversal task in the water maze. Using intracerebral injection, Kobilo et al. (2007) found that WIN55,212-2 has no effect on the extinction of conditioned taste aversion. Thus, the alleviating effects of cannabinoid receptor activation on extinction have not been observed consistently.
Many studies have shown that the administration of $\mathrm{CB}_{1}$ receptor agonists impairs memory (Lichtman et al., 1995; Hampson and Deadwyler, 1999; Davies et al., 2002). However, several other studies have indicated differently, in particular with regards to aversive or fear-based paradigms. For example, $\mathrm{CB}_{1}$ receptor agonist enhances the acquisition of contextual fear conditioning (Mikics et al., 2006) but has no effect on the acquisition of other aversive tasks (De Oliveira Alvares et al., 2008; Yim et al., 2008). Thus, cannabinoids may have various effects that may result from differences in experimental protocols (e.g., aversive vs nonaversive protocols, mass vs spaced extinction trials, time of drug injection or time between extinction learning and testing, central or systemic drug administration, the use of different drugs, etc).

\section{Cannabinoid receptor agonist in the BLA reverses the effects of stress on inhibitory avoidance learning}

Exposing rats to acute stress before conditioning or before/after the first extinction trial enhances inhibitory acquisition/consolidation and disrupts extinction. This corroborates several studies that examined the effects of stress on different memory processes (Cordero et al., 2003; Izquierdo et al., 2006; Akirav and Maroun, 2007). Although administering the cannabinoid receptor agonist into the BLA has no effect on IA conditioning and extinction by itself, environmental stress and cannabinoid receptor activity interact in their regulation of memory in the BLA. Thus, cannabinoid activation in the BLA acts to modulate the effects of stress on conditioning and extinction. In support, Patel et al. (2005) found a synergistic interaction between environmental stress and $\mathrm{CB}_{1}$ receptor activation in the amygdala, because the combination of restraint stress and $\mathrm{CB}_{1}$ agonist administration produces robust Fos induction within the BLA and the central amygdala.

\section{The effects of cannabinoids and stress on corticosterone levels}

Intra-BLA WIN55,212-2 by itself dose dependently enhances CORT levels when compared with the control group, because the higher dose $(5 \mu \mathrm{g} / 0.5 \mu \mathrm{l})$ resulted in more CORT secretion than the lower dose $(2.5 \mu \mathrm{g} / 0.5 \mu \mathrm{l})$. This is consistent with findings that cannabinoid activation in both human and animal models stimulates glucocorticoid secretion (Murphy et al., 1998). Most importantly, the CORT levels of rats microinjected with WIN55,212-2 into the BLA without exposure to the EP stressor do not differ significantly from those of rats microinjected with WIN55,212-2 and then exposed to the stressor. Similarly we found that an intraperitoneal administration of WIN55,212-2 $(0.25 \mathrm{mg} / \mathrm{kg})$ reversed the stressinduced increase in CORT levels. Hence, acute stress elevates corticosterone levels, and $\mathrm{CB}_{1}$ receptor activation in the BLA significantly reduces this stress-induced elevation. These findings may suggest that cannabinoid activation in the BLA modulates the effects of stress on learning, at least partially, via inhibition of the HPA axis. Similarly, Patel et al. (2004) have demonstrated that mice treated systemically with $\mathrm{CB}_{1}$ receptor agonists show significantly decreased or eliminated restraintinduced CORT release. In our study, the abolishment of the effects of stress on CORT levels by WIN55,212-2 was localized to the BLA. Interestingly, microinjecting the $\mathrm{CB}_{1}$ receptor antagonist AM251 (6 ng/0.5 $\mu \mathrm{l})$ also resulted in the enhancement of CORT levels.

A model that explains the possible interaction between the endocannabinoid system, stress and the HPA axis has been 
suggested previously (Patel et al., 2005; Cota, 2008). On exposure to an acute stressor, a reduction in endocannabinoid signaling would result in increased synaptic activity at glutamatergic afferents to the paraventricular nucleus (PVN), thus allowing stressful stimuli to activate the HPA axis (Di et al., 2003; Patel et al., 2004). The BLA has received considerable attention as a stress-regulatory structure, but there is limited evidence of direct innervations of the PVN by the BLA or other intra-amygdalar projections of the BLA, such as the medial and central nuclei (Herman et al., 2003). Hence, the mechanism by which WIN55,212-2 administered into the BLA inhibits the HPA axis during stress needs additional investigation. In any case, it is important to note that pharmacological administration of exogenous cannabinoids may lead to a different action than that induced by the endogenous agents of the endocannabinoid system. Thus, exogenous $\mathrm{CB}_{1}$ receptor activation, as in our study, may not resemble endocannabinoid signaling and its role in HPA axis regulation (Steiner and Wotjak, 2008).

It has been shown recently (Campolongo et al., 2009) that the endocannabinoid system is involved in modulating the consolidation of memory for IA training and that $\mathrm{CB}_{1}$ activity within the BLA is essential for mediating glucocorticoid effects on longterm IA memory. Specifically it has been shown that AM251 administered into the BLA prevented CORT effects on memory consolidation. Steiner et al. (2008) have shown that mice lacking $\mathrm{CB}_{1}$ in cortical glutamatergic neurons showed decreased immobility in the forced swim test with normal corticosterone release compared with controls. In our study, AM251 into the BLA was found to facilitate and impair IA conditioning and extinction, respectively, and to increase CORT levels. Exposure to the EP stress had similar effects on both IA learning and CORT levels. Together, it seems that additional investigation regarding the possible interaction between the $\mathrm{CB}_{1}$ receptor antagonist and the HPA axis is required.

\section{The modulation of emotional processes by cannabinoids}

Cannabis is widely used, primarily because of its euphorant, anti-anxiety, and stress-reducing properties (Green et al., 2003). The effects of cannabinoid agonists on anxiety are biphasic, with low doses being anxiolytic and high doses anxiogenic (Viveros et al., 2005). Although the precise mechanisms by which $\mathrm{CB}_{1}$ receptors modulate neuronal activity within the BLA are not fully understood, various studies have reported that cannabinoids serve to attenuate the neuronal and behavioral responses to aversive environmental stimuli (Patel et al., 2005). Indeed, pharmacological augmentation of cannabinoids reduces anxiety-related behavioral responses (Berrendero and Maldonado, 2002; Kathuria et al., 2003) and suppresses restraint stressinduced corticosterone release (Patel et al., 2004). In addition, cannabinoid exposure was shown to decrease corticotropinreleasing hormone levels in the amygdala, which may account for reduced stress responses (Rodríguez de Fonseca et al., 1997).

Within the BLA, high concentrations of $\mathrm{CB}_{1}$ receptors are found localized on a subpopulation of inhibitory interneurons (McDonald and Mascagni, 2001), suggesting an important regulatory role for $\mathrm{CB}_{1}$ receptor transmission within the BLA through endocannabinoid signaling. Several studies have reported strong inhibition of BLA interneurons after application of $\mathrm{CB}_{1}$ receptor agonists (Azad et al., 2004; Pistis et al., 2004), which is expected to decrease local inhibitory feedback on pyramidal amygdalar outputs neurons. Katona et al. (2001) suggested that, by reducing the tonic GABAergic inhibitory control over pyramidal cells in the BLA, cannabinoids indirectly inhibit neuronal activity in the central nucleus, which mediates stress and fear responses to aversive stimuli. Nevertheless, cannabinoids were found to control synaptic transmission in the lateral amygdala by also modulating glutamatergic synapses (Azad et al., 2003). Thus, this suggests that the effects could also result from $\mathrm{CB}_{1}$-mediated suppression of excitatory neurotransmission.

It has been suggested that the endocannabinoid system has a specific involvement in the habituation component of fear extinction (Kamprath et al., 2006) and that this involvement resembles its role in adaptation of stress responses (Viveros et al., 2005). Patel et al. (2005) showed that the endocannabinoid system mediates habituation to repeated restraint stress and suggested that pharmacological augmentation of endocannabinoid signaling is a good target for the treatment of affective disorders (Patel and Hillard, 2008). Altogether, these studies indicate that extinction of aversive memories via a habituation-like process and the adaptation to stress responses via the alleviation of the stress axis are, in part, controlled by endocannabinoids (for review, see Lutz, 2007).

\section{Conclusions}

Our findings give preclinical support to the suggestion that cannabinoids could represent a therapeutic target for the treatment of diseases associated with the inappropriate retention of aversive memories, such as posttraumatic stress disorder (Marsicano et al., 2002). Importantly, because of the effects of the drug on the stress response, it is likely that potential patients treated with cannabinoids or related compounds might benefit also from the stress-reversing effects of the drug. Nevertheless, studies show that cannabinoids elicit dose-dependent, biphasic effects on emotionality (Onaivi et al., 1990; Haller et al., 2004; Viveros et al., 2007; Moreira et al., 2009). Thus, the dose together with the context in which cannabinoids are administered should be taken into consideration.

\section{References}

Akirav I, Maroun M (2007) The role of the medial prefrontal cortexamygdala circuit in stress effects on the extinction of fear. Neural Plast 2007:30873.

Alberini CM (2005) Mechanisms of memory stabilization: are consolidation and reconsolidation similar or distinct processes? Trends Neurosci 28:51-56.

Azad SC, Eder M, Marsicano G, Lutz B, Zieglgänsberger W, Rammes G (2003) Activation of the cannabinoid receptor type 1 decreases glutamatergic and GABAergic synaptic transmission in the lateral amygdala of the mouse. Learn Mem 10:116-128.

Azad SC, Monory K, Marsicano G, Cravatt BF, Lutz B, Zieglgänsberger W, Rammes G (2004) Circuitry for associative plasticity in the amygdala involves endocannabinoid signaling. J Neurosci 24:9953-9961.

Berrendero F, Maldonado R (2002) Involvement of the opioid system in the anxiolytic-like effects induced by Delta(9)-tetrahydrocannabinol. Psychopharmacology (Berl) 163:111-117.

Campolongo P, Roozendaal B, Trezza V, Hauer D, Schelling G, McGaugh JL, Cuomo V (2009) Endocannabinoids in the rat basolateral amygdala enhance memory consolidation and enable glucocorticoid modulation of memory. Proc Natl Acad Sci U S A 106:4888-4893.

Chhatwal JP, Davis M, Maguschak KA, Ressler KJ (2005) Enhancing cannabinoid neurotransmission augments the extinction of conditioned fear. Neuropsychopharmacology 30:516-524.

Cordero MI, Venero C, Kruyt ND, Sandi C (2003) Prior exposure to a single stress session facilitates subsequent contextual fear conditioning in rats: evidence for a role of corticosterone. Horm Behav 44:338-345.

Cota D (2008) The role of the endocannabinoid system in the regulation of 
hypothalamic-pituitary-adrenal axis activity. J Neuroendocrinol 20: 35-38.

Davies SN, Pertwee RG, Riedel G (2002) Functions of cannabinoid receptors in the hippocampus. Neuropharmacology 42:993-1007.

de Oliveira Alvares L, de Oliveira LF, Camboim C, Diehl F, Genro BP, Lanziotti VB, Quillfeldt JA (2005) Amnestic effect of intrahippocampal AM251, a CB1-selective blocker, in the inhibitory avoidance, but not in the open field habituation task, in rats. Neurobiol Learn Mem 83:119-124.

De Oliveira Alvares L, Genro BP, Diehl F, Quillfeldt JA (2008) Differential role of the hippocampal endocannabinoid system in the memory consolidation and retrieval mechanisms. Neurobiol Learn Mem 90:1-9.

Di S, Malcher-Lopes R, Halmos KC, Tasker JG (2003) Nongenomic glucocorticoid inhibition via endocannabinoid release in the hypothalamus: a fast feedback mechanism. J Neurosci 23:4850-4857.

Dudai Y (2002) Molecular bases of long-term memories: a question of persistence. Curr Opin Neurobiol 12:211-216.

Garcia R, Spennato G, Nilsson-Todd L, Moreau JL, Deschaux O (2008) Hippocampal low-frequency stimulation and chronic mild stress similarly disrupt fear extinction memory in rats. Neurobiol Learn Mem 89:560-566.

Gardner EL, Vorel SR (1998) Cannabinoid transmission and rewardrelated events. Neurobiol Dis 5:502-533.

Green B, Kavanagh D, Young R (2003) Being stoned: a review of selfreported cannabis effects. Drug Alcohol Rev 22:453-460.

Haller J, Bakos N, Szirmay M, Ledent C, Freund TF (2002) The effects of genetic and pharmacological blockade of the $\mathrm{CB} 1$ cannabinoid receptor on anxiety. Eur J Neurosci 16:1395-1398.

Haller J, Varga B, Ledent C, Freund TF (2004) CB1 cannabinoid receptors mediate anxiolytic effects: convergent genetic and pharmacological evidence with CB1-specific agents. Behav Pharmacol 15:299-304.

Hampson RE, Deadwyler SA (1999) Cannabinoids, hippocampal function and memory. Life Sci 65:715-723.

Harloe JP, Thorpe AJ, Lichtman AH (2008) Differential endocannabinoid regulation of extinction in appetitive and aversive Barnes maze tasks. Learn Mem 15:806-809.

Herman JP, Figueiredo H, Mueller NK, Ulrich-Lai Y, Ostrander MM, Choi DC, Cullinan WE (2003) Central mechanisms of stress integration: hierarchical circuitry controlling hypothalamo-pituitary-adrenocortical responsiveness. Front Neuroendocrinol 24:151-180.

Hölter SM, Kallnik M, Wurst W, Marsicano G, Lutz B, Wotjak CT (2005) Cannabinoid CB1 receptor is dispensable for memory extinction in an appetitively-motivated learning task. Eur J Pharmacol 510:69-74.

Izquierdo A, Wellman CL, Holmes A (2006) Brief uncontrollable stress causes dendritic retraction in infralimbic cortex and resistance to fear extinction in mice. J Neurosci 26:5733-5738.

Kamprath K, Marsicano G, Tang J, Monory K, Bisogno T, Di Marzo V, Lutz B, Wotjak CT (2006) Cannabinoid CB1 receptor mediates fear extinction via habituation-like processes. J Neurosci 26:6677-6686.

Kathuria S, Gaetani S, Fegley D, Valiño F, Duranti A, Tontini A, Mor M, Tarzia G, La Rana G, Calignano A, Giustino A, Tattoli M, Palmery M, Cuomo V, Piomelli D (2003) Modulation of anxiety through blockade of anandamide hydrolysis. Nat Med 9:76-81.

Katona I, Rancz EA, Acsady L, Ledent C, Mackie K, Hajos N, Freund TF (2001) Distribution of CB1 cannabinoid receptors in the amygdala and their role in the control of GABAergic transmission. J Neurosci 21:9506-9518.

Kim JJ, DeCola JP, Landeira-Fernandez J, Fanselow MS (1991) N-methylD-aspartate receptor antagonist APV blocks acquisition but not expression of fear conditioning. Behav Neurosci 105:126-133.

Kobilo T, Hazvi S, Dudai Y (2007) Role of cortical cannabinoid CB1 receptor in conditioned taste aversion memory. Eur J Neurosci 25:3417-3421.

Lichtman AH, Dimen KR, Martin BR (1995) Systemic or intrahippocampal cannabinoid administration impairs spatial memory in rats. Psychopharmacology 119:282-290.

Lutz B (2007) The endocannabinoid system and extinction learning. Mol Neurobiol 36:92-101.

Maren S, Chang CH (2006) Recent fear is resistant to extinction. Proc Natl Acad Sci U S A 103:18020-18025.

Maroun M, Akirav I (2008) Arousal and stress effects on consolidation and reconsolidation of recognition memory. Neuropsychopharmacology 33:394-405.

Marsicano G, Wotjak CT, Azad SC, Bisogno T, Rammes G, Cascio MG, Hermann H, Tang J, Hofmann C, Zieglgänsberger W, Di Marzo V, Lutz B (2002) The endogenous cannabinoid system controls extinction of aversive memories. Nature 418:530-534.

Martin WJ, Coffin PO, Attias E, Balinsky M, Tsou K, Walker JM (1999) Anatomical basis for cannabinoid-induced antinociception as revealed by intracerebral microinjections. Brain Res 822:237-242.

McDonald AJ, Mascagni F (2001) Localization of the CB1 type cannabinoid receptor in the rat basolateral amygdala: high concentrations in a subpopulation of cholecystokinin-containing interneurons. Neuroscience 107:641-652

Mikics E, Dombi T, Barsvári B, Varga B, Ledent C, Freund TF, Haller J (2006) The effects of cannabinoids on contextual conditioned fear in CB1 knockout and CD1 mice. Behav Pharmacol 17:223-230.

Miracle AD, Brace MF, Huyck KD, Singler SA, Wellman CL (2006) Chronic stress impairs recall of extinction of conditioned fear. Neurobiol Learn Mem 85:213-218.

Moreira FA, Aguiar DC, Guimarães FS (2007) Anxiolytic-like effect of cannabinoids injected into the rat dorsolateral periaqueductal gray. Neuropharmacology 52:958-965.

Moreira FA, Aguiar DC, Campos AC, Lisboa SF, Terzian AL, Resstel LB, Guimarães FS (2009) Antiaversive effects of cannabinoids: is the periaqueductal gray involved? Neural Plast 2009:625469.

Murphy LL, Muñoz RM, Adrian BA, Villanúa MA (1998) Function of cannabinoid receptors in the neuroendocrine regulation of hormone secretion. Neurobiol Dis 5:432-446.

Myers KM, Davis M (2007) Mechanisms of fear extinction. Mol Psychiatry 12:120-150.

Nader K, Schafe GE, LeDoux JE (2000) The labile nature of consolidation theory. Nat Rev Neurosci 1:216-219.

Niyuhire F, Varvel SA, Thorpe AJ, Stokes RJ, Wiley JL, Lichtman AH (2007) The disruptive effects of the $\mathrm{CB} 1$ receptor antagonist rimonabant on extinction learning in mice are task-specific. Psychopharmacology (Berl) 191:223-231.

Onaivi ES, Green MR, Martin BR (1990) Pharmacological characterization of cannabinoids in the elevated plus maze. J Pharmacol Exp Ther 253:1002-1009.

Pamplona FA, Prediger RD, Pandolfo P, Takahashi RN (2006) The cannabinoid receptor agonist WIN 55,212-2 facilitates the extinction of contextual fear memory and spatial memory in rats. Psychopharmacology 188:641-649.

Pamplona FA, Bitencourt RM, Takahashi RN (2008) Short- and long-term effects of cannabinoids on the extinction of contextual fear memory in rats. Neurobiol Learn Mem 90:290-293.

Patel S, Hillard CJ (2008) Adaptations in endocannabinoid signaling in response to repeated homotypic stress: a novel mechanism for stress habituation. Eur J Neurosci 27:2821-2829.

Patel S, Roelke CT, Rademacher DJ, Cullinan WE, Hillard CJ (2004) Endocannabinoid signaling negatively modulates stress-induced activation of the hypothalamic-pituitary-adrenal axis. Endocrinology 145:5431-5438.

Patel S, Cravatt BF, Hillard CJ (2005) Synergistic interactions between cannabinoids and environmental stress in the activation of the central amygdala. Neuropsychopharmacology 30:497-507.

Paxinos G, Watson C (1998) The rat brain in stereotaxic coordinates. San Diego: Academic.

Pistis M, Perra S, Pillolla G, Melis M, Gessa GL, Muntoni AL (2004) Cannabinoids modulate neuronal firing in the rat basolateral amygdala: evidence for CB1 and non-CB1-mediated actions. Neuropharmacology 46:115-125.

Porter AC, Felder CC (2001) The endocannabinoid nervous system: unique opportunities for therapeutic intervention. Pharmacol Ther 90:45-60.

Reich CG, Mohammadi MH, Alger BE (2008) Endocannabinoid modulation of fear responses: learning and state dependent performance effects. J Psychopharmacol 22:769-777.

Rodríguez de Fonseca F, Carrera MR, Navarro M, Koob GF, Weiss F (1997) Activation of corticotropin-releasing factor in the limbic system during cannabinoid withdrawal. Science 276:2050-2054. 
Sara SJ (2000) Retrieval and reconsolidation: toward a neurobiology of remembering. Learn Mem 7:73-84.

Shors TJ, Weiss C, Thompson RF (1992) Stress-induced facilitation of classical conditioning. Science 257:537-539.

Shumake J, Barrett D, Gonzalez-Lima F (2005) Behavioral characteristics of rats predisposed to learned helplessness: reduced reward sensitivity, increased novelty seeking, and persistent fear memories. Behav Brain Res 164:222-230.

Steiner MA, Wotjak CT (2008) Role of the endocannabinoids system in regulation of the hypothalamic-pituitary-adrenocortical axis. Prog Brain Res 170:397-432.

Steiner MA, Marsicano G, Wotjak CT, Lutz B (2008) Conditional cannabinoid receptor type 1 mutants reveal neuron subpopulation-specific effects on behavioral and neuroendocrine stress responses. Psychoneuroendocrinology 33:1165-1170.

Suzuki A, Josselyn SA, Frankland PW, Masushige S, Silva AJ, Kida S (2004)
Memory reconsolidation and extinction have distinct temporal and biochemical signatures. J Neurosci 24:4787-4795.

Thiel CM, Müller CP, Huston JP, Schwarting RK (1999) High versus low reactivity to a novel environment: behavioural, pharmacological and neurochemical assessments. Neuroscience 93:243-251.

Varvel SA, Lichtman AH (2002) Evaluation of CB1 receptor knockout mice in the Morris water maze. J Pharmacol Exp Ther 301:915-924.

Viveros MP, Marco EM, File SE (2005) Endocannabinoid system and stress and anxiety responses. Pharmacol Biochem Behav 81:331-342.

Viveros MP, Marco EM, Llorente R, Lamota L (2007) The role of the hippocampus in mediating emotional responses to nicotine and cannabinoids: a possible neural substrate for functional interactions. Behav Pharmacol 18:375-389.

Yim TT, Hong NS, Ejaredar M, McKenna JE, McDonald RJ (2008) Post-training CB1 cannabinoid receptor agonist activation disrupts long-term consolidation of spatial memories in the hippocampus. Neuroscience 151:929-936. 